\title{
Proteomic Identification of Differentially Expressed Proteins during Alfalfa (Medicago sativa L.) Flower Development
}

OPEN ACCESS

Edited by:

Pingfang Yang,

Wuhan Botanical Garden, Chinese

Academy of Sciences, China

Reviewed by:

Joshua L. Heazlewood,

University of Melbourne, Australia

Sun-Hee Woo,

Chungbuk National University,

South Korea

Lin Meng,

Beijing Academy of Agricultural and Forestry Sciences, China

*Correspondence:

Peisheng Mao

maopeisheng@hotmail.com

Specialty section: This article was submitted to

Plant Proteomics,

a section of the journa

Frontiers in Plant Science

Received: 27 May 2016 Accepted: 21 September 2016

Published: 04 October 2016

Citation:

Chen L, Chen Q, Zhu Y, Hou L and

Mao $P$ (2016) Proteomic Identification

of Differentially Expressed Proteins during Alfalfa (Medicago sativa L.)

Flower Development.

Front. Plant Sci. 7:1502.

doi: 10.3389/fpls.2016.01502
Lingling Chen ${ }^{1,2}$, Quanzhu Chen ${ }^{3}$, Yanqiao Zhu ${ }^{1}$, Longyu Hou ${ }^{1}$ and Peisheng Mao ${ }^{1 *}$

'Beijing Key Laboratory of Grassland Science, Forage Seed Lab, China Agricultural University, Beijing, China, ${ }^{2}$ Chifeng Academy of Agricultural and Animal Sciences, Chifeng, China, ${ }^{3}$ Chengdu Municipal Development and Reform Commission, Chengdu, China

Flower development, pollination, and fertilization are important stages in the sexual reproduction process of plants; they are also critical steps in the control of seed formation and development. During alfalfa (Medicago sativa L.) seed production, some distinct phenomena such as a low seed setting ratio, serious flower falling, and seed abortion commonly occur. However, the causes of these phenomena are complicated and largely unknown. An understanding of the mechanisms that regulate alfalfa flowering is important in order to increase seed yield. Hence, proteomic technology was used to analyze changes in protein expression during the stages of alfalfa flower development. Flower samples were collected at pre-pollination (S1), pollination (S2), and the postpollination senescence period (S3). Twenty-four differentially expressed proteins were successfully identified, including 17 down-regulated in pollinated flowers, one upregulated in pollinated and senesced flowers, and six up-regulated in senesced flowers. The largest proportions of the identified proteins were involved in metabolism, signal transduction, defense response, oxidation reduction, cell death, and programmed cell death (PCD). Their expression profiles demonstrated that energy metabolism, carbohydrate metabolism, and amino acid metabolism provided the nutrient foundation for pollination in alfalfa. Furthermore, there were three proteins involved in multiple metabolic pathways: dual specificity kinase splA-like protein (kinase spIALs), carbonic anhydrase, and NADPH: quinone oxidoreductase-like protein. Expression patterns of these proteins indicated that MAPK cascades regulated multiple processes, such as signal transduction, stress response, and cell death. PCD also played an important role in the alfalfa flower developmental process, and regulated both pollination and flower senescence. The current study sheds some light on protein expression profiles during alfalfa flower development and contributes to the understanding of the basic molecular mechanisms during the alfalfa flowering process. These results may offer insight into potential strategies for improving seed yield, quality, and stress tolerance in alfalfa.

Keywords: alfalfa, flower, proteomics, pollination, senescence, MAPK, PCD 


\section{INTRODUCTION}

Flowering represents the transition from vegetative growth to the reproductive phase and is a crucial terminal point in a plant's life cycle. Flower development is a complicated process that is generally divided into flower induction, flower evocation, and flower organ formation (Tan and Swain, 2006). Flower sexual organs play an important role in plant sexual reproduction as they generate seeds through the union of pollen and egg cells. Pollination is a key event in the reproductive process for the control of seed setting; it is referred to as the interaction between pollen and the stigma ( $\mathrm{Li}$ et al., 2012). Numerous genes, proteins, and environmental factors are involved in the interaction and influence pollination. However, because of the complexity of the pollen-stigma interaction, only a few flowers and ovules develop into fruits or seeds (Arathi et al., 1999). Proteomics have made great strides in understanding the pollenstigma interaction, and focusing on the research of distinct proteins during the pollen-stigma interaction. Previous studies have mainly focused on the protein expression profile of pollen grains or tubes at different times during pistil development in several species, such as soybean [Glycine max (Linn.) Merr.] (Li et al., 2012), rice (Oryza sativa L.) (Li et al., 2016), corn (Zea mays L.) (Liu et al., 2010) and Liriodendron chinense Hemsl. (Li et al., 2014). However, very little research has focused on protein changes during flower pollination and post-pollination senescence.

Pollination triggers a series of developmental events that contributed to flower senescence in higher plants, for example, flower pigmentation changes, fading and curling of petal edges, petal senescence, etc. Furthermore, petal senescence is a visible symptom, and occurs soon after pollination (Samach and Smith, 2013). Petal senescence caused the flower dehydration, an increase in film permeability exosmosis, extravasation of micromolecular substances, and finally led to cell death and petal withering (van Doorn and Woltering, 2008). Pollination is initiated by signal transduction, and is regulated through ethylene synthesis to initiate the physiological process of petal senescence (Orzaez et al., 1999). Pollination can result in various physiological reactions, such as destructions and death of some of the cells in the pistils. When pollen grains germinate and the pollen tube grows down the pistil, PCD takes place in the

\footnotetext{
Abbreviations: 2DE, two-dimensional electrophoresis; APX, ascorbate peroxidase; $\mathrm{BP}$, biological process; $\mathrm{CA}$, carbonic anhydrase; $\mathrm{CAT}$, catalase; CC, cellular component; CHAPS, 3-[(3-cholamidopropyl) dimethylammonio]-1propane sulfonate; CYB5R, NADH-cytochrome b5 reductase; DTT, dithiothreitol; ECH1s, enoyl-CoA hydratase/delta 3,5-delta 2,4-dienoyl-CoA isomerase; GO, gene ontology; GR, glutathione reductase; GST, glutathione-S-transferase; HR, hypersensitive response; IEF, isoelectric focusing; KEGG, kyoto encyclopedia of genes and genomes; kinase splALs, dual specificity kinase splA-like protein; MDHAR, monodehydroascorbate reductase; MF, molecular function; $\mathrm{Mr}$, molecular mass; MS, mass spectrometry; nanoLC-MS/MS, nanoelectrospray tandem mass spectrometry; NQOLs, NADPH: quinone oxidoreductase-like protein; PCD, programmed cell death; PDILs, protein disulfide isomerase-like protein; PGK, phosphoglycerate kinase; $p \mathrm{I}$, isoelectric point; PRX, peroxidase; qRT-PCR, quantitative real-time PCR; ROS, reactive oxygen species; SAMS, s-adenosylmethionine synthase; SAR, systemic acquired resistance; SDS, sodium dodecyl sulfate; SDS-PAGE, sodium dodecyl sulfate-polyacrylamide gel electrophoresis; SOD, superoxide dismutase; UniProt, universal protein resource.
}

conducting tissues surrounding the pollen tubes (Serrano et al., 2015).

The success of seed setting depends on successful pollination; however, during the flower-to-fruit transition, flower falling, and flower abortion always exists and only few flowers successfully develop seeds (Ruan et al., 2012). Lebon et al. (2008) indicate that seed setting is sustained by nutrients and photoassimilates exported from photosynthetically active leaves through the photosynthesis and the phloem in the inflorescence itself. Ruan et al. (2012) suggest that sugar and hormone signaling regulate seed setting, and glucose acts as a signal molecule to repress the expression of PCD genes and to promote cell division and seed set. However, there is, as yet, little understanding of the mechanism regulating early development during seed set. Postpollination senescence is a complex multi-step process that determines the success of seed formation. The reduction in protein content is viewed as an important symbol of senescence (van Doorn and Woltering, 2008; Bai et al., 2010). Therefore, it was necessary to identify the specific protein and explore its mechanism during flower pollination and post-pollination senescence, as this would be beneficial in the understanding of successful seed setting.

Alfalfa (Medicago sativa L., $2 n=4 x=32$ ) is an important forage in world-wide. It is a typical cross-pollination plant and has the characteristic of self-incompatibility. Alfalfa in the field always exhibits a lower setting percentage and a serious drop flower phenomenon with the actual seed yield at only about $4 \%$ of the theoretical seed yield (Wang Z.F. et al., 2007). Pollination and genetic variation are the main causes of this phenomenon (Martiniello, 1998; Sengul, 2006). Alfalfa has a unique flowering mechanism and a complicated pollination process that depends on external mechanical strength and the honey bee (Zhang et al., 2005). In recent years, great progress has been made in understanding the effects of pollinating insects (Shebl et al., 2009; Riday et al., 2015), tripping mechanisms (Wu and Wei, 2013), and pollination (Mol et al., 2011; Wang et al., 2011) in improving alfalfa seed set percentage. Development of the alfalfa flower is controlled by numerous genes that activate the expression of specific genes and thus the synthesis of specific proteins. Proteomics offer an effective approach to discover the proteins and pathways that are crucial for exploring flower pollination and the mechanism of fertilization at a deeper level. Such findings may be conducive to a deeper understanding of the molecular mechanism of the reproductive development of alfalfa. The current study conducted proteomic analysis on alfalfa flowers during pre-pollination, pollination, and postpollination senescence. The aim of this study was to determine the differentially expressed proteins that are related to pollination and senescence, and to explore the possible roles of differential proteins in early development during the alfalfa seed set phase.

\section{MATERIALS AND METHODS}

\section{Plant Material}

Alfalfa (cv. Aohan) was grown in an experimental field of the Chifeng Academy of Agricultural and Animal Sciences 
(longitude $118.51^{\circ} \mathrm{E}$; latitude $42.17^{\circ} \mathrm{N}$ ) in 2014 . Flowers with an opening on top and all flowering at the same time were selected as samples during the full flowering stage. Artificial pollination was performed in different flowers from the same inflorescence at noon $(12: 00 \mathrm{~h})$. Flower development was divided into three distinct stages: pre-pollinated stage (S1), fully opened with the keels still closed; pollinated stage (S2), $2 \mathrm{~h}$ after pollination; and post-pollination senesced stage (S3), with withering petals and shallow color ( $24 \mathrm{~h}$ after pollination). All the samples were collected and immediately frozen in liquid nitrogen, and stored at $-80^{\circ} \mathrm{C}$ for protein extraction and $\mathrm{qRT}$ PCR assays. All treatments (S1, S2, and S3) were repeated in triplicate.

\section{Protein Extraction}

Total proteins was extracted from developing flowers according to Wang X.C. et al. (2007) in three biological replicates. Flower samples $(2 \mathrm{~g})$ were homogenized in liquid nitrogen. The powdered flowers were suspended in $3 \mathrm{~mL}$ of cold extraction buffer $[50 \mathrm{mM}$ Tris-HCl (pH 8.5), $5 \mathrm{mM}$ EDTA, $100 \mathrm{mM}$ KCL, $2 \%(\mathrm{w} / \mathrm{v}) \quad \beta$-mercaptoethanol, and 31\% (w/v) sucrose], and further ground for $30 \mathrm{~min}$ on ice. Subsequently, an equal volume of Tris-buffered phenol was added and centrifuged at $6000 \times g$ at $4^{\circ} \mathrm{C}$ for $10 \mathrm{~min}$. In the next step, $1 \mathrm{~mL}$ of supernatant was transferred to a $10 \mathrm{~mL}$ microcentrifuge tube and precipitated with four volumes of cooled precipitation solution (methanol containing $0.1 \mathrm{M}$ ammonium) at $-20^{\circ} \mathrm{C}$ overnight; it was then collected by centrifugation at $6000 \times g$ for $10 \mathrm{~min}$. The supernatants were discarded and the pellets were washed three times in cooled precipitation solution and $80 \%(\mathrm{w} / \mathrm{v})$ acetone containing $0.07 \%(\mathrm{w} / \mathrm{v}) \beta$-mercaptoethanol, respectively. Finally, the pellets were air-dried and resuspended in solubilization buffer [7 M Urea, $2 \mathrm{M}$ Thiourea, $40 \mathrm{mMTris,}$ $4 \%(\mathrm{w} / \mathrm{v})$ CHAPS, $1 \mathrm{mM}$ EDTA, and $1 \%(\mathrm{w} / \mathrm{v})$ DTT] at $25^{\circ} \mathrm{C}$ for $1 \mathrm{~h}$. The suspension was centrifuged at $6000 \times g$ for $5 \mathrm{~min}$ at $4^{\circ} \mathrm{C}$ to remove insoluble materials. Protein concentrations were determined by the Bradford method ( $\mathrm{Li}$ et al., 2013) using bovine serum albumin (BSA) as the standard. The quantified protein samples were stored at $-20^{\circ} \mathrm{C}$ until further use.

\section{Two-Dimensional Electrophoresis (2-DE)}

Proteins were initially separated using IEF. For preparative IEF, a ReadyStrip $^{\mathrm{TM}}$ IPG strip (17 cm, pH 3-10, non-linear; BIO$\mathrm{RAD}, \mathrm{USA}$ ) were passively rehydrated overnight with $350 \mu \mathrm{L}$ of rehydration buffer [7 M Urea, 2\% (w/v) CHAPS, 2\% (w/v) DTT, $0.2 \%$ v/v IPG buffers ( $\mathrm{pH} 3-10$, non-linear; GE Healthcare, Uppsala, Sweden), and $0.001 \%$ bromophenol blue] containing $1 \mathrm{mg}$ of protein. IEF was performed for $22.5 \mathrm{~h}$ at $20^{\circ} \mathrm{C}$ using a PROTEAN 112 IEF Cell (BIO-RAD, USA) for a total run of $100 \mathrm{kVh}(50 \mathrm{~V}$ for $6.5 \mathrm{~h}, 200 \mathrm{~V}$ for $1 \mathrm{~h}, 500 \mathrm{~V}$ for $1 \mathrm{~h}, 1 \mathrm{kV}$ for $1 \mathrm{~h}, 5 \mathrm{kV}$ for $2 \mathrm{~h}, 10 \mathrm{kV}$ for $5 \mathrm{~h}$ and subsequently run at $10 \mathrm{kV}$ until the final volt-hours reached $100 \mathrm{kVh}$ ). After IEF, the IPG strips were equilibrated for $15 \mathrm{~min}$ in equilibration buffer [1.5 M Tris- $\mathrm{HCl}(\mathrm{pH} 8.8), 6 \mathrm{M}$ urea, 30\% (v/v) glycerol, 2\% (w/v) SDS, and $0.002 \%$ bromophenol blue] containing $1 \%(\mathrm{w} / \mathrm{v})$ DTT, followed by 15 min in equilibration buffer containing $2.5 \%$ (w/v) iodoacetamide. For second dimensional electrophoresis, gels were transferred to $13 \% \mathrm{w} / \mathrm{v}$ vertical SDS-PAGE gels $(30 \%$ acrylamide/bis, $0.06 \%$ TEMED, 10\% SDS, 10\% ammonium persulfate, and $1.5 \mathrm{M}$ Tris-HCL $\mathrm{pH} 8.8$ ) in PROTEAN II xi Cell (BIO-RAD, USA) until the dye line reached the end of the gel. After electrophoresis, gels were stained overnight with Coomassie Brilliant Blue (PhastGel Blue R-350, GE Healthcare) and scanned at $300 \mathrm{dpi}$ resolution using an image scanner (Bio-5000 plus MICROTEK, China). Image analysis was carried out with PDQuest software (version 8.0.1, BIO-RAD, USA). Each sample was analyzed for three biological replicates. To investigate the flower protein profiles, a comparison was made between pollinated and pre-pollinated flowers. Subsequently, a second comparison was performed of the profiles of senesced flowers, pre-pollinated, and pollinated flowers. Only spots with a significant difference $(p<0.05)$ were considered as varying spots, and the protein spots with an abundance ratio of at least a fourfold change among different flower samples were selected as differentially expressed proteins and then identified by MS.

\section{Protein Identification by NanoLC-MS/MS}

The identified protein spots were cut from 2D gels and digested with $50 \mathrm{mM}$ ammonium bicarbonate in $50 \%$ acetonitrile, then dehydrated in $100 \%$ acetonitrile and dried in a Speed-Vac. The gel pieces were rehydrated with digestion solution $(10 \mathrm{mg} / \mathrm{ml}$ trypsin in $50 \mathrm{mM}$ ammonium) for overnight at $37^{\circ} \mathrm{C}$. The resulting peptides were extracted with $30 \mu \mathrm{L} 30 \%$ acetonitrile and $0.1 \%$ formic acid and shaken for $30 \mathrm{~min}$. This was repeated with $10 \mu \mathrm{L} 60 \%$ acetonitrile and $0.1 \%$ formic acid, and subsequently the peptides were identified using nanoLCMS/MS. The nanoLC separation was achieved with a Waters (Milford, MA, USA) nanoAcquity nano HPLC. Nanospray ESIMS was then performed using a Thermo Q-Exactive high resolution mass spectrometer (Thermo Scientific, Waltham, MA, USA). Raw data from the mass spectrometer were preprocessed with Mascot Distiller 2.5 for peak picking. The resulting peak lists were searched against the Medicago truncatula EST database of the NCBInr protein database using the Mascot 2.5 search engine. The following parameters were used in the search: trypsin enzyme specificity with a maximum of two missed cleavage, carbamidomethylation of cysteine (fixed modifications), methionine oxidation (variable modifications), peptide mass tolerance (10 ppm), and fragment mass tolerance $(0.02 \mathrm{Da})$. Among the positive matches, protein identifications based on at least two independent peptides with an individual ion score $>26$ or only one peptide having a ions score $>45$ was accepted, and the coverage of the protein by the matching peptides should be higher than $5 \%$, and the expect threshold $p$-value was less than 0.05 for the Mascot search. All information of matched peptides is given in Supplementary Table 1. Theoretical molecular mass (Mr) and isoelectric point $(p \mathrm{I})$ of identified proteins were predicted by ExPASy server ${ }^{1}$ to check the $\mathrm{Mr}$ and $\mathrm{pI}$ of identified proteins.

\footnotetext{
${ }^{1}$ http://www.expasy.org/protparam
} 


\section{qRT-PCR Analysis}

For each flower developmental stage, three replicate samples were randomly chosen and total RNA was extracted from developing flowers using TRNzol Reagent (TIANGEN Biotech, Beijing, China) according to the manufacturer's instructions. First-strand cDNA was synthesized with specific primers (Supplementary Table 2) using PrimeScript ${ }^{\mathrm{TM}}$ RT reagent Kit with gDNA Eraser (TaKaRa, Dalian, China) according to the manufacturer's instructions. qRT-PCR was conducted on an ABI Prism 7500 Detection System (Applied Biosystems) using SYBR Premix Taq Kit (TaKaRa, Dalian, China) according to the manufacturer's instructions. A volume of $20 \mu \mathrm{L}$ of real time PCR reaction mixture contained $2 \mu \mathrm{L}$ of first-strand cDNAs, $0.5 \mu \mathrm{L}$ of $10 \mu \mathrm{M}$ gene-specific primers (F, R), $10 \mu \mathrm{L}$ of $2 \times$ SYBR Green Master Mix I, and $7 \mu \mathrm{L}$ of $\mathrm{ddH}_{2} \mathrm{O}$. PCR reaction conditions were as follows: $95^{\circ} \mathrm{C}$ for $30 \mathrm{~s}$ followed by 45 cycles at $95^{\circ} \mathrm{C}$ for $5 \mathrm{~s}$, and at $60^{\circ} \mathrm{C}$ for $40 \mathrm{~s}$. The $\beta$-actin gene was used as a reference gene. The relative quantification $\left(2^{-\Delta \Delta C T}\right)$ of gene expression was evaluated using the comparative cycle threshold method.

\section{Functional Annotation and Classification}

To determine the functional classification and biological properties of identified proteins, the identified protein sequences were mapped with GO Terms. For this, a homology search was performed for all the identified sequences with a localized NCBI BLAST searched against the NCBInr Medicago truncatula database. GO annotation was performed using BLAST2GO ${ }^{2}$ (Conesa and Gotz, 2008). The identified proteins were classified into three functional categories: CC, BP, and MF. In addition, all mapped sequences were annotated to the KEGG database ${ }^{3}$ accessions to obtain protein domain information. In order to obtain reliable information, we used a hypergeometric test to perform GO enrichment and pathway enrichment. $P$-values of every GO term and KEGG pathway were calculated using the hypergeometric test and those where $P<0.05$ were denoted as having significant enrichment.

\section{Hierarchical Cluster Analysis of Protein Abundance}

Protein abundance values were estimated using PDQuest software (version 8.0.1, BIO-RAD, USA). Each sample was analyzed for three biological replicates. Hierarchical cluster analysis was implemented in $\mathrm{R}$ (version 3.2.2) after normalization of the expression abundance values.

\section{Statistical Analysis}

All experiments were replicated in triplicate. Spot intensities, GO functional enrichment, KEGG pathway, and relative quantity of expressed genes were all analyzed statistically using analysis of variance (ANOVA) by SPSS 21.0. Treatment means were separated using Duncan's multiple range test taking $p<0.05$ as significant.

${ }^{2} \mathrm{http} / /$ www.blast2go.com

${ }^{3}$ http://www.Kegg.jp/kegg/pathway.html

\section{RESULTS}

\section{Protein Profiles of Alfalfa Flower at Different Developing Stages}

According to the 2-DE with the IPG strips ( $\mathrm{pH} 3-10$, nonlinear; Figure 1), the abundances of matched spots in the three replicate images were normalized and transformed using PDQuest image software. A comparison of 2-DE images revealed that there were 25 spots differed by more than fourfold (or below fourfold) in abundance between pre-pollinated, pollinated and senesced flowers. Finally, 24 spots were successfully identified by LC-MS/MS mass spectroscopy identification using a search against the Mascot software and Uniprot database retrieval (Table 1). The identified proteins could be divided into two types (Figure 2): pre-pollination expressions and post-pollination expressions proteins. Compared with un-pollinated flowers, 17 proteins (spots 1-17) were down-regulated after pollination, and seven proteins (spots 18-24) were up-regulated after pollination; most of them (spots 19-24) were expressed in senescing flowers. One spot (spot 12) did not produce a positive identification and two spots belonged to the same protein (spots 1 and 7). Furthermore, the experimental $\mathrm{Mr}$ of all identified proteins ranged from 13.61 to $48.81 \mathrm{KDa}$, the theoretical $\mathrm{Mr}$ range was from 13.66 to $48.02 \mathrm{KDa}$, and the experimental and theoretical $\mathrm{pI}$ of all identified proteins were both within the range of 4.95 to 9.47. Most of them fall within the ranges of $p$ I 5.0-6.5 and $\mathrm{Mr}$ $16-48 \mathrm{kDa}$ (Table 1).

\section{Functional Annotation and Classification of Identified Proteins}

According to BP, CC, and MF, 24 expressed proteins were divided into 29 GO terms (Figure 3; Supplementary Table 3). The major functional categories in the BP were metabolic processes (16 proteins, $76.19 \%$ ), cellular processes (15 proteins, $71.43 \%$ ), and response to stimulus (14 proteins, 66.67\%). For CC, cell (20 proteins, 100\%), cell part (20 proteins, 100\%), and organelle (17 proteins, $85 \%$ ) were the most abundant groups, whereas binding (11 proteins, $64.71 \%)$ and catalytic activity (11 proteins, $64.71 \%$ ) accounted for the most abundant groups in terms of MF. GO enrichment was further performed to elucidate the biological functions of proteins identified in alfalfa developing flowers. The results showed that there were only five proteins significantly enriched in BP and CC (Figure 4). Protein kinase cascade (spots 8,17, and 24), systemic acquired resistance (spots 8, 17, and 24), plant-type hypersensitive response (spots 8,17 , and 24), host PCD induced by symbiont (spots 8,17 , and 24 ), cell death (spots 8,17 , and 24), PCD (spots 8, 17, and 24), defense response, and incompatible interaction (spots 2, 8, 17, and 24) were significantly enriched in the BP category. Furthermore, intramolecular oxidoreductase activity (spots 2 and 20) and hydro-lyase activity (spots 8, 17, and 24) were enriched in the CC category. This result indicated that the main functions of identified proteins were signal transmission, defense response, oxidation reaction, and cell death during alfalfa flower development. Detailed enrichment information is presented in Supplementary Table 4. 

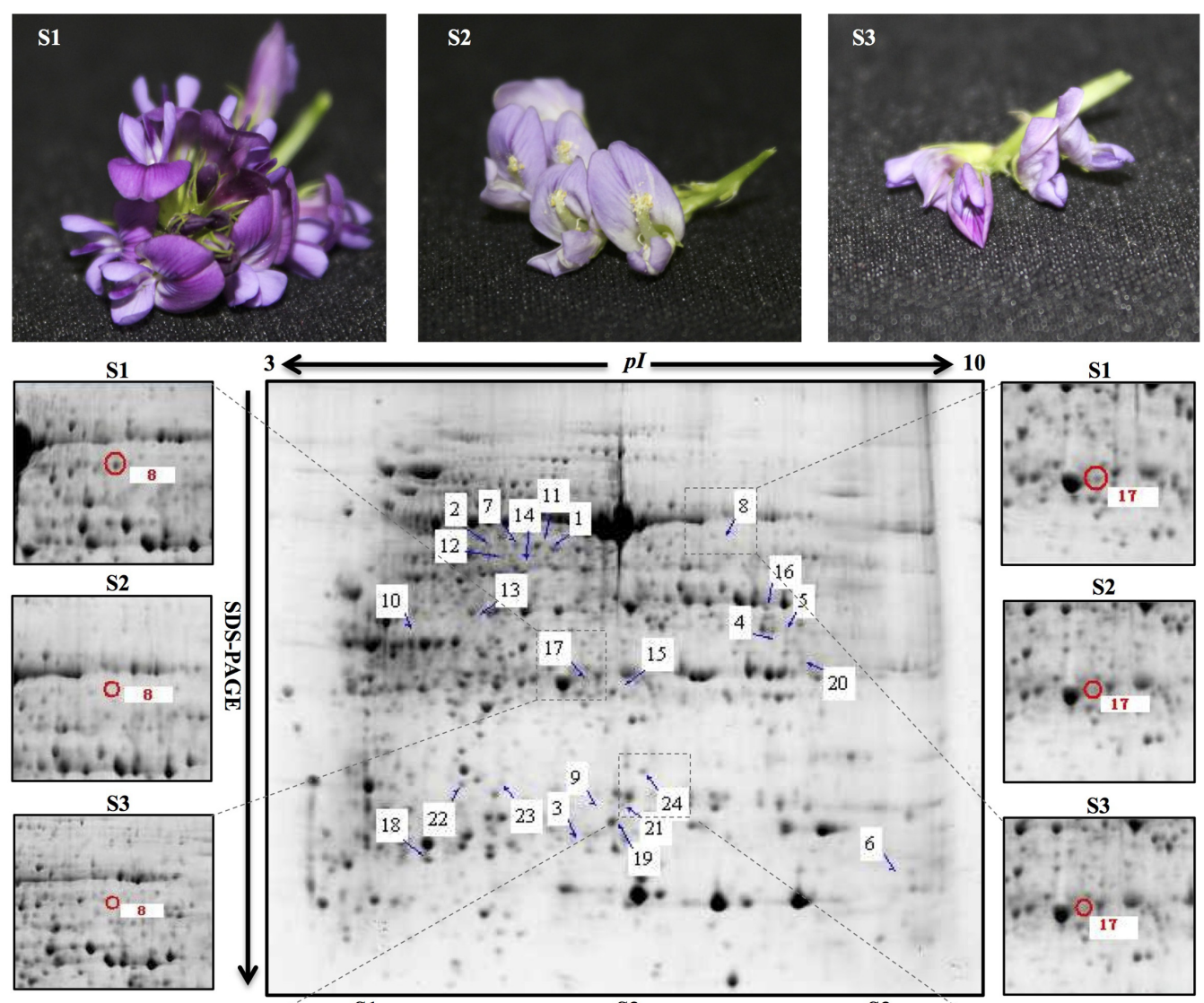

S3
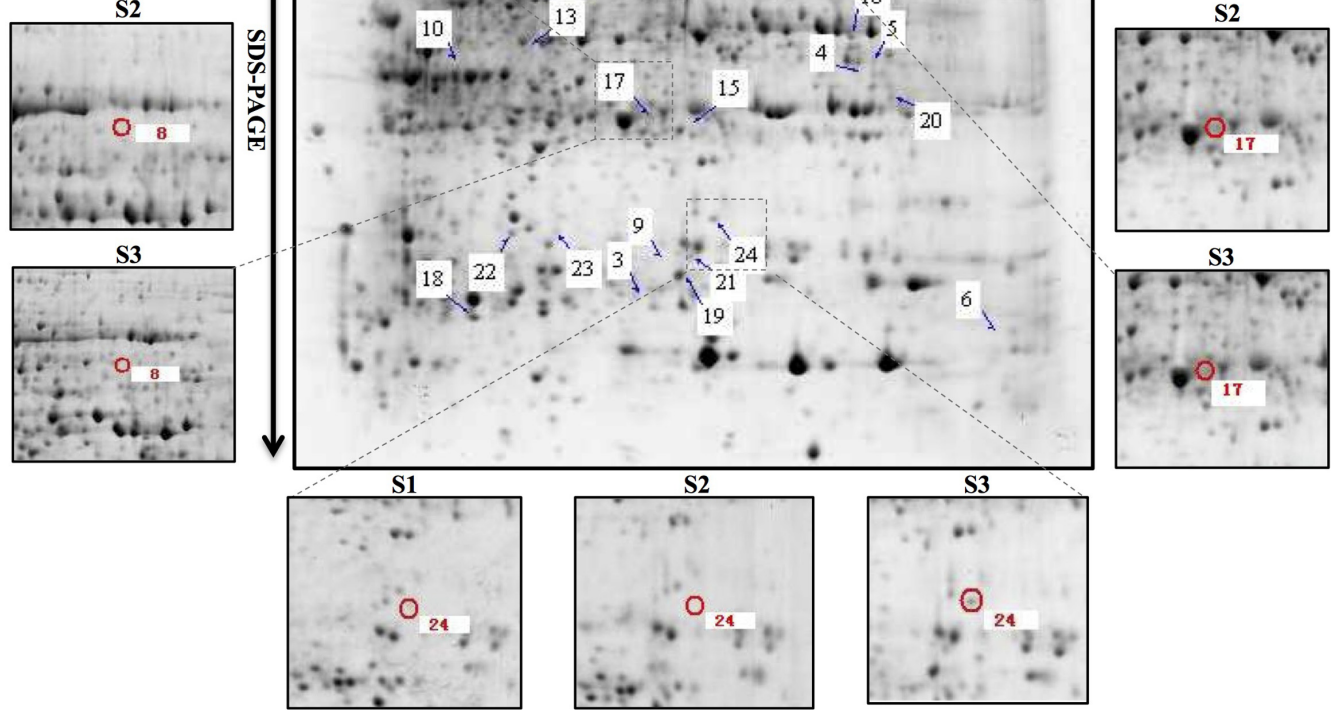

FIGURE 1 | Representative 2-DE pattern of total protein fraction from developing alfalfa flowers. S1: pre-pollinated stage (fully opened with the keels still closed); S2: pollinated stage (2 h after pollination); S3: post-pollination senesced stage ( $24 \mathrm{~h}$ after pollination). Arrows indicate protein spots that were increased or decreased in abundance. Zoomed images show the main differentially expressed protein spots in developing alfalfa flowers. Spot 8 and 17: down-regulation in S2 and S3; spot 24: up-regulation in S3. The three biological replicates of the 2-DE gels are shown in Supplementary Figure 1.

In addition, KEGG analysis was used to understand the biochemical pathways of differentially expressed proteins. A total of 13 proteins were assigned to 28 pathways (Supplementary Table 5). Among these pathways, selenoamino acid metabolism was significantly enriched according to functional enrichment analysis; the related protein was SAMS (spots 1 and 7). According to standard types of KEGG pathway map, identified proteins mainly mapped as six types (metabolism, genetic information processing, environmental information processing, cellular processes, organismal systems, and human diseases) and 15 sub-types (Supplementary Table 5). Furthermore, four proteins (spots 1, 4, 7, and 14) participated in global and overview maps, carbohydrate metabolism, energy metabolism, amino acid metabolism, and metabolism of other amino acids. Four proteins (spots 2, 6, 15, and 19) participated in translation, folding, sorting, and degradation. One protein (spot
8) participated in signal transduction; two proteins (spots 3 and 20) participated in transport and catabolism, and cell motility; two proteins (spots 3 and 8 ) participated in the immune system, development, and cell communication; and two proteins (spots 8 and 16) participated in neurodegenerative diseases and infectious diseases.

\section{Transcriptional Expression Analysis of Selected Genes by qRT-PCR}

To confirm the proteomic results, qRT-PCR was used to examine the seven randomly selected proteins (spots $2,7,8,14,17,20$, and 24) at mRNA level using specific primers (Supplementary Table 2). Compared with the S1 stage, spots 2, 7, 8, and 24 were up-regulated at the S2 and S3 stages, spots 14 and 20 were down-regulated at the S2 and S3 stages, spot 17 was downregulated at S3 while up-regulated at the S2 stage. The expression 
TABLE 1 | Differentially expressed proteins identified by LC-MS/MS during alfalfa flower development.

\begin{tabular}{|c|c|c|c|c|c|c|c|}
\hline Spot & Protein ID & Protein name & Accession no. ${ }^{a}$ & Score $^{b}$ & $\begin{array}{l}\text { Coverage } \\
(\%)^{c}\end{array}$ & $\begin{array}{l}\text { Theoretical } \\
\mathrm{Mr} / \mathrm{pl}^{\mathrm{d}}\end{array}$ & $\begin{array}{l}\text { Experimental } \\
\qquad \mathrm{Mr} / \mathrm{pl}^{\mathrm{e}}\end{array}$ \\
\hline 1 & A0A072V8Q4 & S-adenosylmethionine synthase & gi| 922390587 & 7797 & 79 & $43.60 / 5.77$ & $43.17 / 5.77$ \\
\hline 2 & G7IDU4 & $\begin{array}{l}\text { Protein disulfide isomerase-like } \\
\text { protein }\end{array}$ & gi| 922396181 & 747 & 42 & $40.74 / 5.38$ & $40.43 / 5.38$ \\
\hline 3 & G7IFU0 & $\begin{array}{l}\text { Cofilin/actin-depolymerizing } \\
\text { factor-like protein }\end{array}$ & gil 357448329 & 1319 & 65 & $16.24 / 6.16$ & $16.08 / 6.16$ \\
\hline 4 & G7L2L3 & $\begin{array}{l}\mathrm{NADH} \text {-cytochrome b5 } \\
\text { reductase }\end{array}$ & gi| 357508929 & 79 & 17 & $31.01 / 8.30$ & $30.86 / 8.30$ \\
\hline 5 & Q2HRU6 & $\begin{array}{l}\text { Xyloglucan } \\
\text { endotransglucosylase/hydrolase }\end{array}$ & gi| 357508519 & 90 & 8 & $34.47 / 8.42$ & $34.15 / 8.42$ \\
\hline 6 & G7IF49 & Ribosomal L22e family protein & gi| 357442479 & 158 & 48 & $13.66 / 9.47$ & $13.61 / 9.47$ \\
\hline 7 & G7KUJ1 & S-adenosylmethionine synthase & gil 357511493 & 6386 & 77 & $43.71 / 5.59$ & $43.28 / 5.59$ \\
\hline 8 & A0A072UY58 & $\begin{array}{l}\text { Dual specificity kinase splA-like } \\
\text { protein }\end{array}$ & gi| 922369199 & 328 & 29 & $47.52 / 7.80$ & $47.38 / 7.80$ \\
\hline 9 & A0A072UB69 & $\begin{array}{l}\text { Mediator of RNA polymerase II } \\
\text { transcription subunit } 7\end{array}$ & gi| 922353693 & 161 & 17 & $19.43 / 6.08$ & $19.38 / 6.08$ \\
\hline 10 & $\mathrm{~B} 7 \mathrm{FHQ} 2$ & $\begin{array}{l}\text { Alpha-soluble NSF attachment } \\
\text { protein }\end{array}$ & gi| 357461465 & 63 & 17 & $32.99 / 5.03$ & $32.61 / 5.03$ \\
\hline 11 & G8A1N5 & $\begin{array}{l}\text { Chromosome condensation } \\
\text { regulator } \mathrm{RCC} 1 \text { repeat protein }\end{array}$ & gi| 357464765 & 1705 & 55 & $48.02 / 5.68$ & $47.39 / 5.68$ \\
\hline 12 & AOA072UTH6 & Uncharacterized protein & gi| 922377082 & 278 & 22 & $41.15 / 5.46$ & $48.81 / 5.15$ \\
\hline 13 & A0A072TF84 & Annexin & gil 922325593 & 177 & 23 & $35.72 / 5.44$ & $44.18 / 5.13$ \\
\hline 14 & G7IT87 & Phosphoglycerate kinase & gi| 357451633 & 3666 & 66 & $42.65 / 5.61$ & $42.62 / 5.61$ \\
\hline 15 & I3S2M3 & $\begin{array}{l}\text { GTP-binding nuclear Ran-like } \\
\text { protein }\end{array}$ & gil 922383336 & 80 & 23 & $25.54 / 6.38$ & $25.22 / 6.38$ \\
\hline 16 & A0A072VSG1 & $\begin{array}{l}\text { RNA polymerase } \\
\text { II-associated-like protein }\end{array}$ & gi| 922399794 & 224 & 33 & $37.45 / 8.58$ & $37.18 / 8.58$ \\
\hline 17 & G7KIR1 & Carbonic anhydrase & gil 357495991 & 392 & 34 & $28.45 / 6.10$ & $28.19 / 6.10$ \\
\hline 18 & G7INB7 & ABA-responsive protein & gil 357449145 & 717 & 52 & $16.60 / 4.95$ & $16.61 / 4.95$ \\
\hline 19 & AOA072VEB8 & $\begin{array}{l}\text { Cytosolic class II small } \\
\text { heat-shock protein }\end{array}$ & gil 922397253 & 69 & 9 & $17.91 / 6.31$ & $17.87 / 6.31$ \\
\hline 20 & G7JC24 & $\begin{array}{l}\text { Enoyl-CoA hydratase/delta3,5- } \\
\text { delta2,4-dienoyl-CoA } \\
\text { isomerase }\end{array}$ & gi| 922375826 & 325 & 33 & $29.69 / 5.34$ & $29.42 / 8.56$ \\
\hline 21 & G719Z6 & $\begin{array}{l}\text { Calcium-dependent } \\
\text { lipid-binding (CaLB domain) } \\
\text { family protein }\end{array}$ & gi| 357438759 & 240 & 33 & $19.85 / 6.59$ & $19.46 / 6.59$ \\
\hline 22 & G718G3 & Cation transporter ChaC & gil 357438635 & 65 & 14 & 20.99/5.34 & $20.89 / 5.34$ \\
\hline 23 & G7L7T5 & $\begin{array}{l}\text { Pathogenesis-related protein } \\
\text { bet V I family protein }\end{array}$ & gi| 357515823 & 156 & 31 & $18.18 / 5.50$ & $18.02 / 5.50$ \\
\hline 24 & B7FMX0 & $\begin{array}{l}\text { NADPH:quinone } \\
\text { oxidoreductase-like protein }\end{array}$ & gil 357515109 & 45 & 7 & $21.14 / 6.52$ & $21.15 / 6.52$ \\
\hline
\end{tabular}

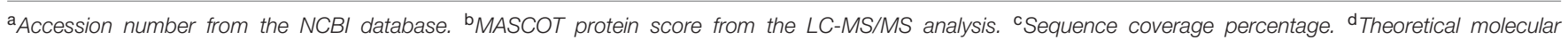
weight/isoelectric point. experimental molecular weight/isoelectric point.

profiles of two genes (spots 14 and 24) at mRNA levels were consistent with those at protein levels, four gene's (spots 2, 3, 7, and 8) expression tendency at mRNA levels were opposite to their protein levels. The mRNA and protein expression levels of spot 17 were inconsistent at the S2 stage and consistent in the S3 stage (Figure 5).

\section{DISCUSSION}

In this experiment, there were 24 proteins with over fourfold (or below fourfold) changes in abundance that were identified and functionally classified based on GO functional annotation and KEGG metabolism pathway analysis. Identified proteins were mainly related to metabolism, signal transduction, stress response and oxidation reduction, and cell death.

\section{Metabolism-Related Proteins Expressed during Alfalfa Flower Development}

It was found that the largest group of differentially expressed proteins was related to metabolism during alfalfa flower development (Figure 3; Supplementary Table 5). Most of them were involved in carbohydrate metabolism, energy metabolism, 


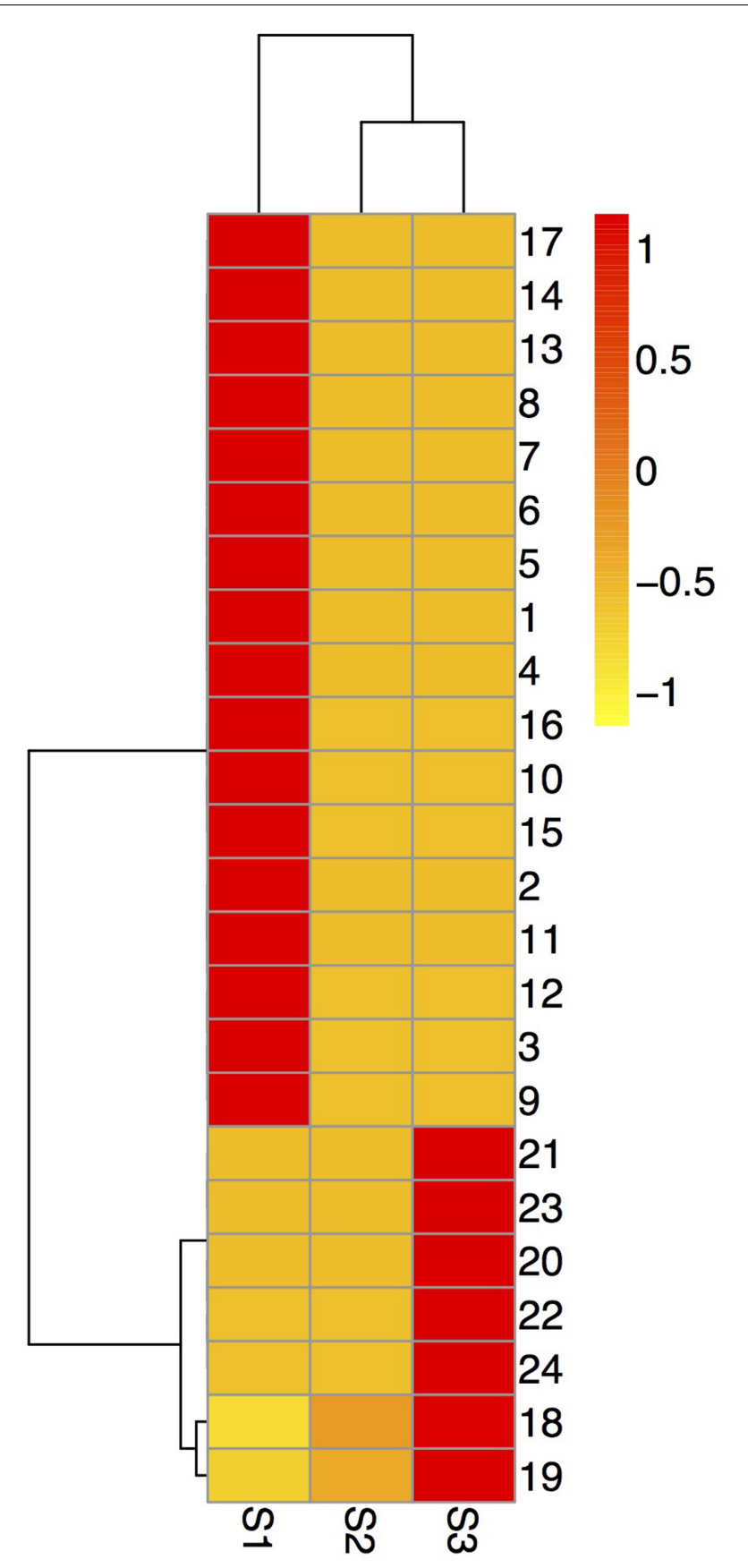

FIGURE 2 | Hierarchical cluster analysis of the expressed proteins during alfalfa flower development. Dataset clustering was implemented in $R$ (version 3.2.2) after normalization of the expression abundance values. Each colorized cell represents the averaged spot quantity, according to the color scale on the right of the figure. S1: pre-pollinated stage (fully opened with the keels still closed); S2: pollinated stage (2 h after pollination); S3: post-pollination senesced stage (24 h after pollination); 1-24: spot number.

and amino acid metabolism (Supplementary Table 5), and were up-regulated before pollination and down-regulated after pollination, which indicated that the primary metabolisms was enhanced to facilitate pollination. This result was consistent with previous studies in rice (Li et al., 2016) and soybean (Li et al., 2012), which suggests that enhancement of primary metabolisms in the pistil may enhance successful pollination in plants. Some common metabolic reactions, such as glycolysis, the TCA cycle, and amino acid synthesis, exist globally in plant organs and tissues. The intensity of these metabolic reactions could directly reflect plant growth conditions (Carrari and Fernie, 2006; Fait et al., 2006). Metabolismrelated proteins account for $41.67 \%$ of all identified proteins during soybean flower development (Ahsan and Komatsu, 2009), and related proteins and genes account for 31 and 22\% during the flowering transition of Agapanthus (Zhang et al., 2013). In the current study, metabolism-related proteins accounted for $38.46 \%$ of all identified proteins during alfalfa flower development, indicating that material and energy metabolism had played a crucial role during alfalfa flower development.

Phosphoglycerate kinase (spot 14) participated in glycolysis/gluconeogenesis, CYB5R (spot 4) participated in amino sugar and nucleotide sugar metabolism, and both were up-regulated in the S1 stage, but down-regulated in the S2 and S3 stages (Figures 1 and 2). PGK is a major enzyme involved in glycolysis and is present in all living organisms. In the glycolysis pathway, PGK catalyzes the 1,3-bisphosphoglycerate to ADP producing 3-phosphoglycerate and ATP. In the gluconeogenesis pathway, PGK catalyzes the reverse reaction (Brice et al., 2004). A deficiency of this enzyme could cause disorder in the organism's metabolic function. Sugars have a central regulatory function in plant metabolism and growth, and are essential for germination, blooming, aging, and the stress response. Studies have shown that high concentrations of the most abundant sugars are accumulated during the early stages of floral bud development, and down-regulated during the mature pollen stage in the male sterile hybrid pummelo, indicating that the accumulated sugars supply nutrition for pollen development (Zheng et al., 2014). Sugars only were detected during pollen tube growth in Pinus strobus (Fernando, 2005). Similar results were observed in this study and proteins related the high accumulation of carbohydrates metabolism were up-regulated before pollination, would supply the nutrition and energy for pollen development in alfalfa flower.

Amino acids also increased during the pollination of alfalfa flowers. Cysteine and methionine are of great nutritional importance during flower development because of the limited amounts in the vegetative tissues of many plants (Azevedo et al., 2006). In the current study, SAMS (Spots 1, 7) participated in cysteine, methionine, and selenoamino acid metabolism. SAMS, an important metabolite of living bodies, catalyzed the formation of $S$-adenosylmethionine from methionine and ATP. This is a methyl donor and allows DNA methylation, it is also a precursor of polyamines and ethylene biosynthesis (Woodson et al., 1992). Ethylene is known as a plant growth regulator and it controls various biochemical reactions. Polyamine is the secondary metabolite for improving plant resistance, regulating plant growth and development, postponing senescence, and controlling morphology and architecture. It had been suggested that polyamine could regulate the plant flowering process and 


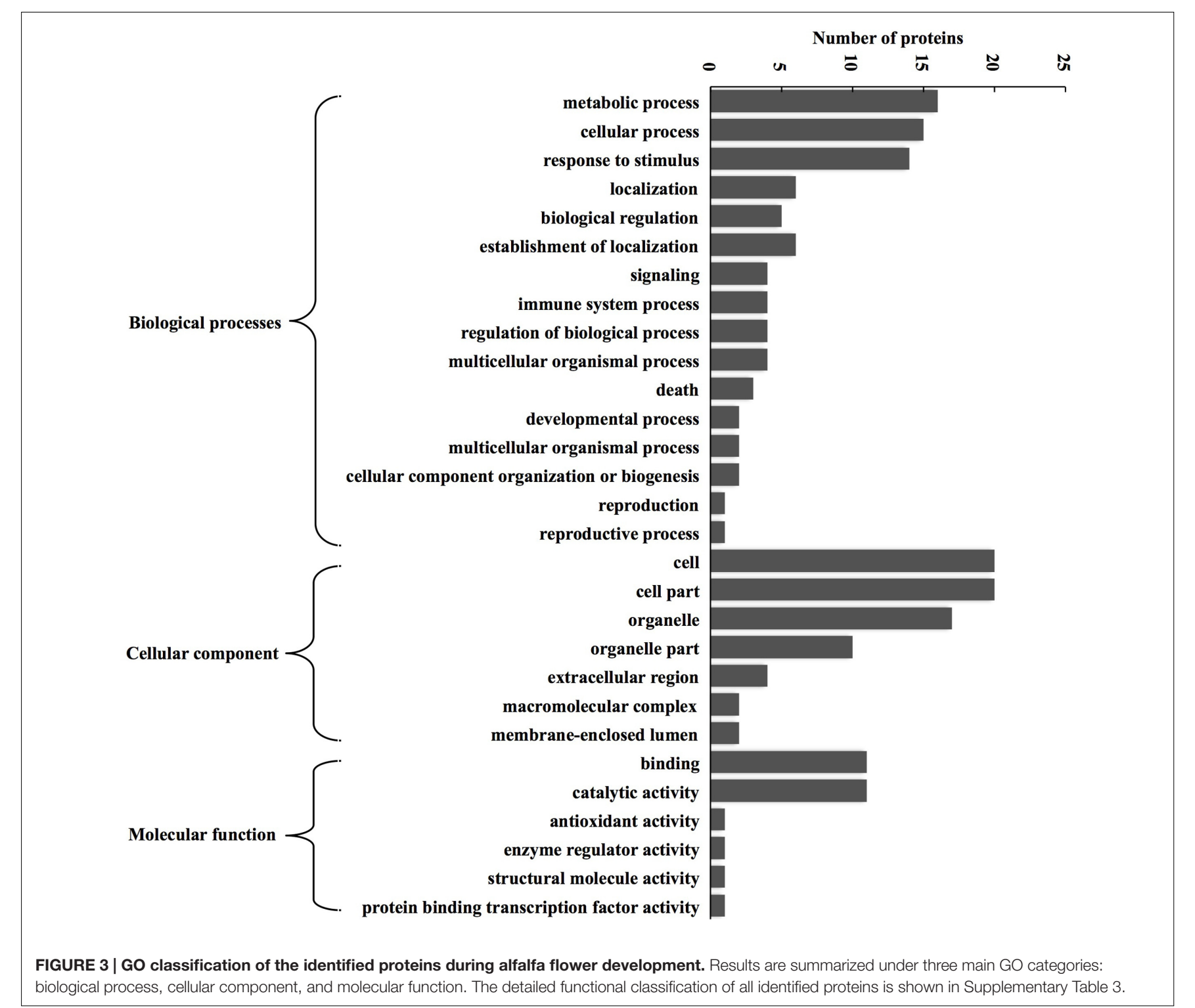

thus promote plant fertilization (Aloisi et al., 2016). In the current study, SAMS were up-regulate in the S1 stage, then downregulated in the S2 and S3 stages (Figures 1 and 2). This process was consistent with previous studies in the stenospermocarpic table grape (Vitis vinifera L.) (Domingos et al., 2016) and Petunia (Bai et al., 2010), which indicated that SAMS were up-regulated before pollination and participated in amino acid metabolism; they were then down-regulated during corolla senescence.

Phosphoglycerate kinase (spot 14) and CA (spot 17) participated in energy metabolism. CA is involved in the nitrogen metabolism pathway; it was expressed in S1 and down-regulated in the S2 and S3 stages (Figures 1 and 2). With multiple cellular functions including nitrogen metabolism, photosynthesis, and water use efficiency, CA serves as an important photosynthesis enzyme during photosynthetic $\mathrm{CO}_{2}$ fixation, and enhances the efficiency of photosynthetic $\mathrm{CO}_{2}$ fixation by catalytic conversion of $\mathrm{HCO}_{3}$ to $\mathrm{CO}_{2}$ and facilitating $\mathrm{CO}_{2}$ supply to the cells
(Badger and Price, 1994). PGK participates in the carbon fixation pathway in photosynthetic organisms. These two proteins were all related to photosynthesis. These results indicated that during the flowering process, adequate carbon sources and energy for alfalfa flower development were provided by photosynthesis. This has been confirmed in two other species, Malus domestica (Zeng et al., 2010) and Brassica napus (Sheoran and Sawhney, 2010).

\section{MAPK Signaling Regulates Flower Pollination and Senescence}

Pollination is a crucial step in the success of seed production in flowering plants (Franklin-Tong, 2002), and exhibits various forms of cell identification and cell signal transduction. Once pollen tubes penetrate the stigma, various signaling molecules serve as key regulators for pollen tube growth. This series of dynamic cell events take place during successful fertilization and flower development (Krichevsky et al., 2007). MAPK 


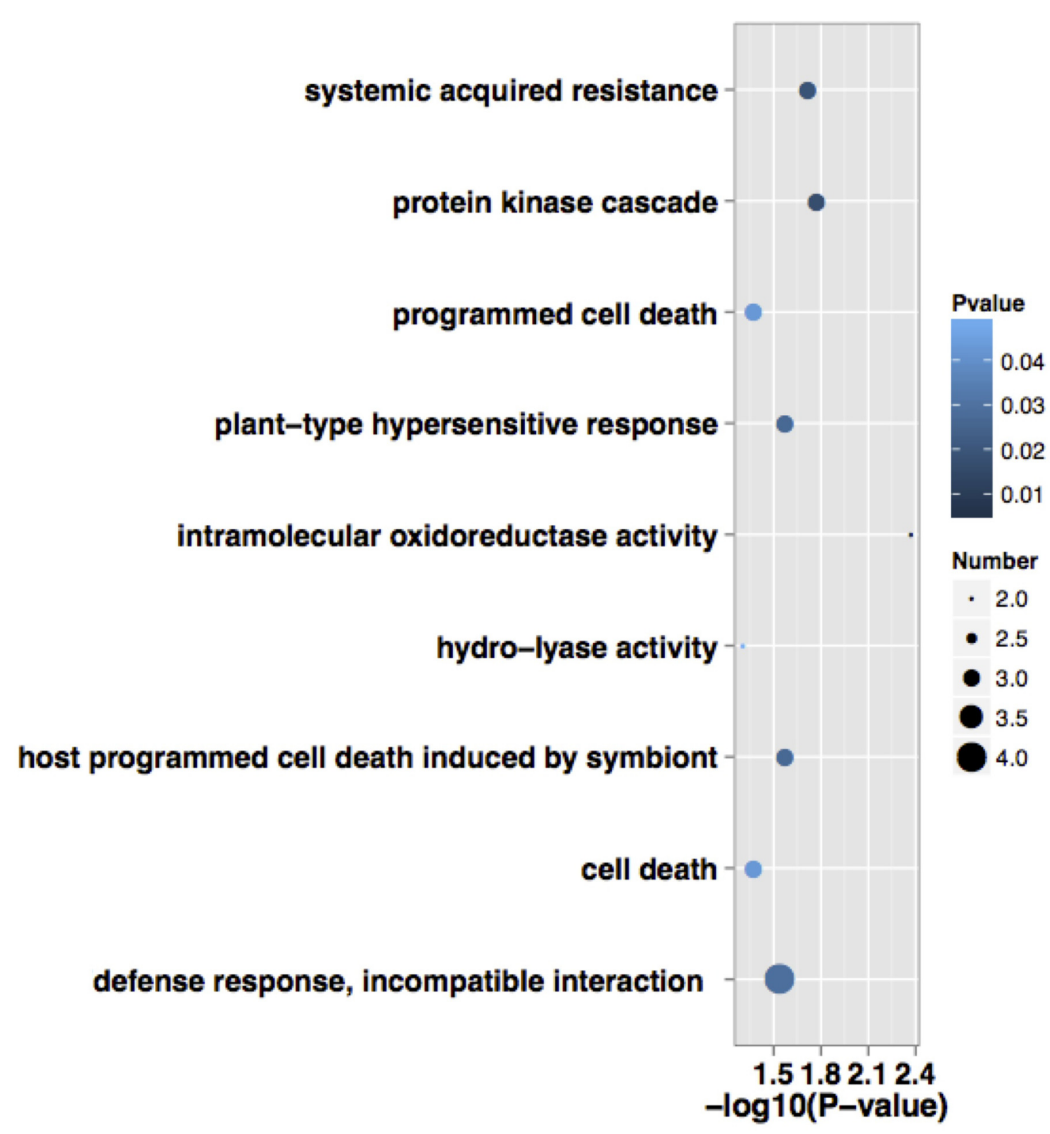

FIGURE 4 | Functional significant enrichment of the identified proteins during alfalfa flower development. Point size indicate the numbers of annotated differential proteins, color depth indicate the $P$-value of enrichment. The detailed significant enrichment of all identified proteins are shown in Supplementary Table 4.

cascades are ubiquitous signaling modules in plants and are involved in every aspect of plant growth and development, including anther development, ovule development, pollen development, pollen tube guidance, fertilization, morphogenesis, gametogenesis, embryo-genesis, abscission, senescence, and seed formation (Xu and Zhang, 2015). It had been shown that MPK3/MPK6 was regulates inflorescence architecture and pollen tube guidance in Arabidopsis. Double MPK3 MPK6 mutant pollen exhibited normal pollen tube growth and a normal micropylar; however, the pollen tube did not enter into the micropylar to complete fertilization, indicating that MPK3/MPK6 function was specifically involved in signal recognition between pollen tubes and the micropylar (Guan et al., 2014).

In the current study, dual specificity kinase splA-like protein (kinase splALs; spot 8), CA (spot 17), and NADPH: quinone oxidoreductase-like protein (NQOLs; spot 24) were significantly enriched during protein kinase cascades according to GO enrichment analysis (Figure 4; Supplementary Table 4). In KEGG pathway analysis, kinase splALs (spot 8) were mapped during signal transduction of environmental information processing, which contained MAPK signal pathways and Wnt signal pathways (Supplementary Table 5). MAPK signal pathways were detected in both GO enrichment analysis and KEGG pathway analysis.

Kinase splALs is a type of PTKs; it participates in signal transduction, cell growth, cell proliferation, and cell differentiation, and is a key element of eucaryon development (Nuckolls et al., 1996). In the present research, kinase splALs were up-regulated in the S1 stage, but down-regulated in the S2 and S3 stages (Figures 1 and 2). They also participated in the MAPK signal transduction pathway and other signal transduction pathways. These results indicated that kinase splALs were important signaling molecules during alfalfa pollination. As a zinc-containing metalloenzyme, CA can catalyze the reversible hydration reaction of $\mathrm{CO}_{2}$, and has been regarded as an important photosynthetic enzyme (Atkins et al., 1972). Light signals can regulate changes in plant structure and form, such as flower initiation, leaf expansion, stem elongation, and seed germination. CA might regulate a series of light-dependent reactions in alfalfa flower. NQOLs were up-regulated in the S3 stages (Figures 1 and 2), and mRNA levels of NQOLs were up-regulated in the S2 and S3 stages (Figure 5). However, no detailed information about any special functions is available to date. Further functional identification of these proteins would disclose their potential roles in flower senescence. 


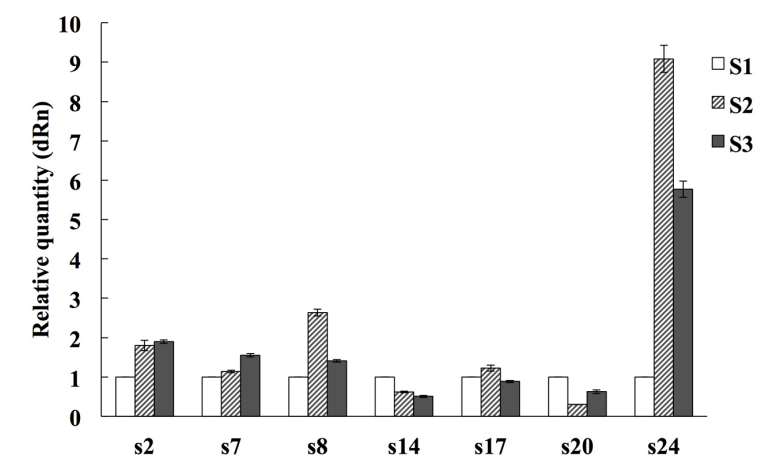

FIGURE 5 | Quantitative Real time PCR analysis on mRNA transcription of the selected expressed proteins during alfalfa flower development. S1: pre-pollinated stage (fully opened with the keels still closed); S2: pollinated stage (2 h after pollination); S3: post-pollination senesced stage (24 h after pollination). The average expression of each gene was calculated relatively to the reference gene $\beta$-actin. This experiment was conducted three biological replicates. The relative expression value of each gene was normalized to an endogenous control and calculated using the $2^{-\Delta \Delta C T}$ methods. All primer sequences are listed in Supplementary Table 2.

\section{Proteins Participating in Stress Response and Oxidative Reaction}

Pollination is often affected by environmental conditions, such as temperature and pathogenic attack, etc. Furthermore, senescing petals cause a series of physiological changes, such as loss of membrane permeability, an increase in ROS, up-regulation of oxidative enzymes, and a decline in activity of certain protective enzymes (Rubinstein, 2000). Previous research has argued that there may be an overlap in the gene regulation pathways of pollination and the stress response (Lan et al., 2005). Kinase splALs (spot 8), CA (spot 17), and NQOLs (spot 24) also participate in the stress response process, and were significantly enriched during SAR, plant-type hypersensitive response, defense response, and incompatible interaction (Figure 4; Supplementary Table 4). SAR is a type of resistance response that occurs following an earlier localized exposure to a pathogen. An early response to pathogens in plants is the rapid death of cells in the local region surrounding an infection; this acts to prevent the spread of pathogens to other plant parts. This process is called the $\mathrm{HR}$, which ultimately leads to SAR, thus enabling a resistance of the secondary infection of the pathogen (Ryals et al., 1996). Activation of MAPK cascades is one of the earliest signaling events after plant recognition of pathogen/microbe-associated molecular patterns (PAMPs/MAMPs) and pathogen effectors. It is involved in multiple defense responses, including ROS generation, HR, biosynthesis of plant stress hormones, stomatal closure, defense gene activation, phytoalexin biosynthesis, cell wall strengthening, and cell death (Ren et al., 2002). Plants detect PAMPs through pattern recognition receptors (PRRs) as attacked by pathogenic bacteria, and the MAPK cascades are responsible for accepting PRRs signals and transmitting them to downstream signal elements (Meng and Zhang, 2013). Previous reports state that tomato plants (Lycopersicon esculentum Mill) activate $S I M A P K K K \alpha$ to regulate PCD, and respond to a pathogenic attack (Oh and Martin, 2011). The SlMAPKKKE gene is related with allergic reaction and could enhance the bacterial resistance in the tomato plant (Melech-Bonfil and Sessa, 2010). Kinase splALs participated in several disease-related pathways in present study.

The reduction of CA could influence the light absorption capacity of chloroplast and thus inhibit photosystem functions and cause oxidative damage. Rice leaves maintain a high photosynthetic rate under drought conditions, which may be related to a higher CA drought responses ability (Dai et al., 2000). Yu et al. (2006) analyzed the transcription characteristics of CA in rice under drought and salt stress conditions. They found that CA expression level was up-regulated with the prolonged of drought and salt stress. They showed that there was a definite relation between rice CA and response adversity. In the current study, NQOLs protein in the stress response group was up-regulated during the S3 stages (Figures 1 and 2). A possible explanation is that NADPH: quinone oxidoreductase could detoxify quinone and their derivatives also reduced organelle or genetic material damage caused by the transformation of quinones, and thus maintains normal physiological functions (Gaikwad et al., 2001). The expression level of NQOLs has been shown to be significantly up-regulated (4.4-fold) in tomato leaves under salt stress (Zhou et al., 2009), whereas the mRNA levels of the corresponding EST gene are increased twofold compared with untreated seedlings (Zhou et al., 2007).

Furthermore, PDILs (spot 2) and ECH1s (spot 20) participated in the redox process (Figure 4; Supplementary Table 4). Electron transfer during photosynthesis and respiration is often accompanied by ROS generation. Although ROS serves as the secondary messenger in many developmental processes, excessive ROS causes oxidative damage to CCs. The evolutionary strategy of plants against oxidative damages is to generate various protective enzymes (Esfandiari et al., 2007). As one member of thioredoxin, PDILs (spot 2) showed the ability to catalyze oxidation, reduction, and isomerization of disulfide bonds in proteins that possessed chaperone and calcium ion binding sites. ECH1s (spot 20) was a mitochondrial $\beta$-oxidation, that was mapped in peroxisome metabolism (Supplementary Table 5). Peroxisome is functional in anti-disease and anti-aging processes, and is a small eukaryotic organelle within a single membrane that is specialized for carrying out oxidative reactions. Senescence is a genetically regulated oxidative process that is mainly characterized by changes of activated oxygen metabolism of peroxisomes, SOD isozymes, and ascorbate-glutathione cycle of peroxisomes (del Rio et al., 1998). Changes in activated oxygen metabolism of peroxisomes are mainly reflected by a disappearance of cascade activity and overexpression of active oxygen. It has been reported that PRX, APX, SOD, ascorbate reductase, and GSH-dependent dehydroascorbate reductase participate in the scavenging of ROS, resist internal and external stresses, and reduce oxidative stress reaction in mature rice pollen (Dai et al., 2006). Proteins related with ROS have been detected during soybean pollination. It was found that APX was up-regulated while glutaredoxin and peroxiredoxin were down-regulated after pollination, indicating that APX could detoxify hydrogen peroxide's response to high ROS levels 
during soybean pollination (Li et al., 2012). ROS accumulates significantly in the stigma after pollination in rice, and SOD, APX, MDHAR, GST, CAT, and GR are expressed to different levels and participate in the scavenging of ROS (Li et al., 2016). During alfalfa flower senescence, up-regulated ECH1s had an activated oxygen-mediated role. Besides, PDILs, kinase splALs, CA, and NQOLs enriched in incompatible interaction (Figure 4; Supplementary Table 4), supposed that the down-regulation of CA with hydrolyase activity might have hindered the hydration reaction and reduced the water content of the stigma, and subsequently inhibited the water absorption and germination of pollen grains, and caused incompatibility between pollen and stigma. However, whether these proteins participated in the stigma-pollen interaction and the related mechanisms needs to be studied further.

\section{PCD Regulating Both Flower Pollination and Senescence in Alfalfa}

It is well known that most changes in flowers are caused by pollination, such as ovary growth, pigmentation changes, and petal senescence. Pollination-induced senescence in petals is an essential event during sexual reproduction. It is considered a synonym of PCD, because the terms of senescence and PCD both denote the processes that initiate the programmed death of individual cells (Rubinstein, 2000). Flower senescence shows many similarities to PCD, including enhancement of hydrolytic enzymes, degradation of macromolecules, and increased in respiratory activity. Hydrolyzed products such as carbohydrates, proteins, lipids, and nucleic acids are then transported to newly growing tissues (De Michele et al., 2009). Abortion of the megaspore and microspore, degeneration of pistil primordium cells, petal withering, and pollen maturation are all accomplished through PCD during plant sexual reproduction (Rogers, 2013). Studies show that all flower cells exhibit PCD between flower induction and embryo development apart from egg cells that develop into the embryo after fertilization (Greenberg, 1996). When the pollen tube enters the stigma, the epidermal cells initiate the PCD to provide nutrition for pollen tube growth (Gonzalez et al., 1996; Greenberg, 1996).

For alfalfa flowers, it was found that 17 proteins disappeared and 7 proteins were up-regulated during post-pollination senescence. Kinase splALs (spot 8), CA (spot 17), and NQOLs (spot 24) were enriched in cell death and PCD functions according to GO functional enrichment analysis (Figure 4; Supplementary Table 4). Kinase splALs and CA presented to down-regulated during post-pollination senescence, while NQOLs were up-regulated (Figures 1 and 2). The decline of CA related with photosynthesis and nitrogen metabolism (Supplementary Table 5) was beneficial for transportation and the reuse of nitrogen sources and nutrients in reproductive organs. Kinase splALs, CA, and NQOLs also participated in MAPK signal transduction and the defense response (Supplementary Table 4). In plants, MAPK pathways are involved in the regulation of growth, development, PCD, and defense responses (Colcombet and Hirt, 2008); they also regulate plant HR cell death and PCD through disrupting the redox balance (Ren et al., 2002; SaucedoGarcia et al., 2015). In the current study, the MAPK cascade may have regulated alfalfa petal senescence through the accumulation of kinase splALs, CA, and NQOL; however, the mechanism of senescence and cell death induced by the activation of MAPK was not clear. Although many proteins are differentially expressed during petal senescence, the functions of only a few are known.

\section{Comparing Protein and mRNA Levels}

Simultaneous monitoring of RNA and protein expressions was performed to understand the mutual regulation between proteins and transcription levels. mRNA levels represent an intermediate state of gene expression and reflect potential protein expression. Nevertheless, some previous research considers that mRNA levels are not always consistent with protein levels, and that there is a negative correlation between mRNA and protein accumulation patterns (Mochida and Shinozaki, 2011; Lan et al., 2012). Integrated expression analysis on proteins and transcription levels could describe the overall gene-gene interaction network, and provide the function of single genes, thus enabling the exploration of its biological functions. The qRT-PCR results in alfalfa showed that only $37 \%$ of identified proteins were similar in their mRNA level, and indicated that the mRNA level couldn't completely represent protein expression. Most differentially expressed proteins were not successfully identified according to qRT-PCR, which showed that these identified proteins might be influenced by time, environment, and other factors. Although qRT-PCR results were not completely consistent with proteome results, their similarity reached $37 \%$, which was adequate to support the expression levels of the proteome in general. Many studies report a negative correlation between mRNA level and protein level (Zhuang et al., 2013; Nakaminami et al., 2014), existing research emphasizes the combination of transcriptome and proteome (Shemesh-Mayer et al., 2015; Li et al., 2016).

Proteins identified during alfalfa flower development are mainly related to metabolism, signal transportation, stress response, and cell death. Most proteins are involved in multiple metabolic pathways, such as the MAPK signaling pathway, stress response, oxidation reaction, and PCD. The current study provides new insight into flower developmental patterns. The results indicated that flower pollination and senescence might not be dependent upon the ethylene signal transduction pathway; however, MAPK cascades were involved in the signal transduction pathway and regulated alfalfa flower development; PCD also regulated both pollination and senescence. Related proteins such as splALs, CA, and NQOLs were vital to flower development in alfalfa. Future research will combine transcriptomes, metabolomes, and morphology in an attempt to understand crosstalk between different functional pathways and complicated regulatory mechanisms.

\section{AUTHOR CONTRIBUTIONS}

PM designed the study and revised the manuscript. LC carried out the study and wrote the manuscript. QC and YZ conducted the experimental work. LH carried out the bioinformatics analysis. All authors discussed the results and reviewed the manuscript. 


\section{ACKNOWLEDGMENTS}

This research was financially supported by earmarked fund for the China Agriculture Research System (CARS-35), and Beijing Common Construction Project.

\section{REFERENCES}

Ahsan, N., and Komatsu, S. (2009). Comparative analyses of the proteomes of leaves and flowers at various stages of development reveal organ-specific functional differentiation of proteins in soybean. Proteomics 9, 4889-4907. doi: 10.1002/pmic.200900308

Aloisi, I., Cai, G., Serafini-Fracassini, D., and Del, D. S. (2016). Polyamines in pollen: from microsporogenesis to fertilization. Front. Plant Sci. 7:155. doi: 10.3389/fpls.2016.00155

Arathi, H. S., Ganeshaiah, K. N., Shaanker, R. U., and Hedge, S. G. (1999). Seed abortion in Pongamia pinnata (Fabaceae). Am. J. Bot. 86, 659-662. doi $10.2307 / 2656574$

Atkins, C. A., Patterson, B. D., and Graham, D. (1972). Plant carbonic anhydrase. 1. Distribution of type among species. Plant Physiol. 50, 214-217. doi 10.1104/pp.50.2.214

Azevedo, R. A., Lancien, M., and Lea, P. J. (2006). The aspartic acid metabolic pathway, an exciting and essential pathway in plants. Amino Acids 30, 143-162. doi: 10.1007/s00726-005-0245-2

Badger, M. R., and Price, G. D. (1994). The role of carbonic anhydrase in photosynthesis. Annu. Rev. Plant Physiol. Plant Mol. Boil. 45, 369-392. doi 10.1146/annurev.pp.45.060194.002101

Bai, S., Willard, B., Chapin, L. J., Kinter, M. T., Francis, D. M., Stead, A. D. et al. (2010). Proteomic analysis of pollination-induced corolla senescence in petunia. J. Exp. Bot. 61, 1089-1109. doi: 10.1093/jxb/erp373

Brice, D. C., Bryant, J. A., Dambrauskas, G., Drury, S. C., and Littlechild, J. A. (2004). Cloning and expression of cytosolic phosphoglycerate kinase from pea (Pisum sativum L.). J. Exp. Bot. 55, 955-956. doi: 10.1093/jxb/erh096

Carrari, F., and Fernie, A. R. (2006). Metabolic regulation underlying tomato fruit development. J. Exp. Bot. 57, 1883-1897. doi: 10.1093/jxb/erj020

Colcombet, J., and Hirt, H. (2008). Arabidopsis MAPKs: a complex signalling network involved in multiple biological processes. Biochem. J. 413, 217-226. doi: 10.1042/BJ20080625

Conesa, A., and Gotz, S. (2008). Blast2GO: a comprehensive suite for functional analysis in plant genomics. Int. J. Plant Genomics 2008:619832. doi: $10.1155 / 2008 / 619832$

Dai, S., Li, L., Chen, T., Chong, K., Xue, Y., and Wang, T. (2006). Proteomic analyses of Oryza sativa mature pollen reveal novel proteins associated with pollen germination and tube growh. Proteomics 6, 2504-2529. doi: 10.1002/pmic.200401351

Dai, X. B., Zhai, H. Q., Zhang, H. S., and Zhang, R. X. (2000). Effect of soil drought stress on photosynthetic rate and carbonic anhydrase activity of rice leaf. Acto Phytophysiol. Sin. 26, 133-136.

De Michele, R., Formentin, E., Todesco, M., Toppo, S., Carimi, F., Zottini, M., et al. (2009). Transcriptome analysis of Medicago truncatula leaf senescence similarities and differences in metabolic and transcriptional regulations as compared with Arabidopsis, nodule senescence and nitric oxide signaling. New Phytol. 181, 563-575. doi: 10.1111/j.1469-8137.2008.02684.x

del Rio, L. A., Pastori, G. M., Palma, J. M., Sandalio, L. M., Sevilla, F., Corpas, F. J., et al. (1998). The activated oxygen role of peroxisomes in senescence. Plant Physiol. 116, 1195-1200. doi: 10.1104/pp.116.4.1195

Domingos, S., Fino, J., Paulo, O. S., Oliveira, C. M., and Goulao, L. F. (2016). Molecular candidates for early-stage flower-to-fruit transition in stenospermocarpic table grape (Vitis vinifera L.) inflorescences ascribed by differential transcriptome and metabolome profiles. Plant Sci. 244, 40-56. doi: 10.1016/j.plantsci.2015.12.009

Esfandiari, E. O., Shakiba, M. R., Mahboob, S. A., Alyari, H., and Toorchi, M. (2007). Water stress, antioxidant enzyme activity and lipid peroxidation in wheat seedling. J. Food Agric. Environ. 5, 149-153.

Fait, A., Angelovici, R., Less, H., Ohad, I., Urbanczyk-Wochniak, E., Fernie, A. R., et al. (2006). Arabidopsis seed development and germination is associated

\section{SUPPLEMENTARY MATERIAL}

The Supplementary Material for this article can be found online at: http://journal.frontiersin.org/article/10.3389/fpls.2016. 01502

with temporally distinct metabolic switches. Plant Physiol. 142, 839-854. doi: 10.1104/pp.106.086694

Fernando, D. D. (2005). Characterization of pollen cube development in Pinus strobus (Eastern white pine) through proteomic analysis of differentially expressed proteins. Proteomics 5, 4917-4926. doi: 10.1002/pmic.200500009

Franklin-Tong, V. E. (2002). The difficult question of sex: the mating game. Curr. Opin. Plant Biol. 5, 14-18. doi: 10.1016/S1369-5266(01)00217-5

Gaikwad, A., Long, D. J., Stringer, J. L., and Jaywalk, A. K. (2001). In vivo role of $\mathrm{NAD}(\mathrm{P}) \mathrm{H}$ : quinone oxidoreductase 1 (NQO1) in the regulation of intracellular redox state and accumulation of abdominal adipose tissue. J. Biol. Chem. 276, 22559-22564. doi: 10.1074/jbc.M101053200

Gonzalez, M. V., Coque, M., and Herrero, M. (1996). Pollen-pistil interaction in kiwifruit (Actinidia deliciosa; Actinidiaceae). Am. J. Bot. 83, 148-154. doi $10.2307 / 2445931$

Greenberg, J. T. (1996). Programmed cell death: a way of life for plants. Proc. Natl. Acad. Sci. U.S.A. 93, 12094-12097. doi: 10.1073/pnas.93.22.12094

Guan, Y. F., Lu, J. P., Xu, J., McClure, B., and Zhang, S. Q. (2014). Two mitogen-activated protein kinases, MPK3 and MPK6, are required for funicular guidance of pollen tubes in Arabidopsis. Plant Physiol. 165, 528-533. doi: $10.1104 /$ pp.113.231274

Krichevsky, A., Kozlovsky, S. V., Tian, G. W., Chen, M. H., Zaltsman, A., and Citovsky, V. (2007). How pollen tubes grow. Dev. Biol. 303, 405-442. doi: 10.1016/j.ydbio.2006.12.003

Lan, L., Li, M., Lai, Y., Xu, W., Kong, Z., Ying, K., et al. (2005). Microarray analysis reveals similarities andvariations in genetic programs controlling pollination/fertilization and stress responses in rice (Oryza sativa L.). Plant Mol. Biol. 59, 151-164. doi: 10.1007/s11103-005-3958-4

Lan, P., Li, W., and Schmidt, W. (2012). Complementary proteome and transcriptome profiling in phosphate-deficient Arabidopsis roots reveals multiple levels of gene regulation. Mol. Cell. Proteomics 11, 1156-1166. doi: 10.1074/mcp.M112.020461

Lebon, G., Wojnarowiez, G., Holzapfel, B., Fontaine, F., Vaillant-Gaveau, N., and Clement, C. (2008). Sugars and flowering in the grapevine (Vitis vinifera L.). J. Exp. Bot. 59, 2565-2578. doi: 10.1093/jxb/ern135

Li, G. Z., Peng, X. Q., Xuan, H. M., Wei, L. T., Yang, Y. Y., Guo, T. C., et al. (2013). Proteomic analysis of leaves and roots of common wheat (Triticum aestivum L.) under copper-stress conditions. J. Proteome Res. 12, 4846-4861. doi: $10.1021 / \mathrm{pr} 4008283$

Li, M., Sha, A. H., Zhou, X. N., and Yang, P. F. (2012). Comparative proteomic analyses reveal the changes of metabolic features in soybean (Glycine max) pistils upon pollination. Sex Plant Reprod. 25, 281-291. doi: 10.1007/s00497012-0197-0

Li, M., Wang, K., Li, S. Q., and Yang, P. F. (2016). Exploration of rice pistil responses during early post-pollination through a combined proteomic and transcriptomic analysis. J. Proteomics 131, 214-226. doi: 10.1016/j.jprot.2015.11.004

Li, M., Wang, K., Wang, X., and Yang, P. F. (2014). Morphological and proteomic analysis reveal the role of pistil under pollination in Liriodendron chinense (Hemsl.) Sarg. PLoS ONE 9:e99970. doi: 10.1371/journal.pone. 0099970

Liu, H. H., Wang, L. W., Liu, N., Liu, X., Ma, X., Ning, L. H., et al. (2010). Proteomic analyses of the early pollen-silk interaction in maize. Sci. Agric. Sin. 43, 5000-5008. doi: 10.3864/j.issn.0578-1752.2010.24.003

Martiniello, P. (1998). Influence of agronomic factors on the relationship between forage production and seed yield in perennial forage grasses and legumes in a Mediterranean environment. Agronomie 18, 591-601. doi: 10.1051/agro:19980809

Melech-Bonfil, S., and Sessa, G. (2010). Tomato MAPKKK epsilon is a positive regulator of cell-death signaling networks associated with plant immunity. Plant J. 64, 379-391. doi: 10.1111/j.1365-313X.2010.04333.x 
Meng, X. Z., and Zhang, S. Q. (2013). MAPK cascades in plant disease resistance signaling. Annu. Rev. phytopathol. 51, 245-266. doi: 10.1146/annurev-phyto082712-102314

Mochida, K., and Shinozaki, K. (2011). Advances in omics and bioinformatics tools for systemsanalyses of plant functions. Plant Cell Physiol. 52, 2017-2038. doi: $10.1093 / \mathrm{pcp} / \mathrm{pcr} 153$

Mol, R., Weigt, D., and Broda, Z. (2011). Cytoembryological analysis of causes for poor seed set in alfalfa (Medicago sativa L.). Acta Biol. Cracov. Bot. 53, 96-101. doi: 10.2478/v10182-011-0013-4

Nakaminami, K., Matsui, A., Nakagami, H., Minami, A., Nomura, Y., Tanaka, M., et al. (2014). Analysis of differential expression patterns of mRNA and protein during cold-and de-acclimation in Arabidopsis. Mol. Cell. Proteomics 13, 36023611. doi: 10.1074/mcp.M114.039081

Nuckolls, G. H., Osherov, N., Loomis, W. F., and Spudich, J. A. (1996). The Dictyostelium dual-specificity kinase splA is essential for spore differentiation. Development 122, 3295-3305.

Oh, C. S., and Martin, G. B. (2011). Tomato 14-3-3 protein TFT7 interacts with a MAP kinase kinase toregulate immunity-associated programmed cell death mediated by diverse disease resistance proteins. J. Biol. Chem. 286, 1412914136. doi: 10.1074/jbc.M111.225086

Orzaez, D., Blay, R., and Granell, A. (1999). Programme of senescence in petals and carpels of Pisum sativum L. flowers and its control by ethylene. Planta 208, 220-226. doi: 10.1007/s004250050553

Ren, D. T., Yang, H. P., and Zhang, S. Q. (2002). Cell death mediated by MAPK is associated with hydrogenperoxide production in Arabidopsis. J. Biol. Chem. 277, 559-565. doi: 10.1074/jbc.M109495200

Riday, H., Reisen, P., Raasch, J., Santa-Martinez, E., and Brunet, J. (2015). Selfing rate in an alfalfa seed production field pollinated with leafcutter bees. Crop Sci. 55, 1087-1095. doi: 10.2135/cropsci2014.04.0295

Rogers, H. J. (2013). From models to ornamentals: how is flower senescence regulated? Plant Mol. Biol. 82, 563-574. doi: 10.1007/s11103-012-9968-0

Ruan, Y. L., Patrick, J. W., Bouzayen, M., Osorio, S., and Fernie, A. R. (2012). Molecular regulation of seed and fruit set. Trends Plant Sci. 17, 656-665. doi: $10.1016 /$ j.tplants.2012.06.005

Rubinstein, B. (2000). Regulation of cell death in flower petals. Plant Mol. Biol. 44, 303-318. doi: 10.1023/A:1026540524990

Ryals, J. A., Neuenschwander, U. H., Willits, M. G., Molina, A., Steiner, H. Y., and Hunt, M. D. (1996). Systemic acquired resistance. Plant Cell 8, 1809-1819. doi: $10.1105 /$ tpc.8.10.1809

Samach, A., and Smith, H. M. (2013). Constraints to obtaining consistent annual yields inperennials. II: environment and fruit load affect induction of flowering. Plant Sci 207, 168-176. doi: 10.1016/j.plantsci.2013.02.006

Saucedo-Garcia, M., Gavilanes-Ruiz, M., and Arce-Cervantes, O. (2015). Longchain bases, phosphatidic acid, MAPKs, and reactive oxygen species as nodal signal transducers in stress responses in Arabidopsis. Front. Plant Sci. 6:55. doi: $10.3389 /$ fpls.2015.00055

Sengul, S. (2006). Using path analysis to determine Lucerne (Medicago sativa L.) seed yield and its components. N. Z. J. Agric. Res. 49, 107-115. doi: 10.1080/00288233.2006.9513700

Serrano, I., Romero-Puertas, M. C., Sandalio, L. M., and Olmedilla, A. (2015). The role of reactive oxygen species and nitric oxide in programmed cell death associated with self-incompatibility. J. Exp. Bot. 63, 1479-1493. doi: 10.1093/jxb/erv083

Shebl, M. A., Kamel, S. M., Hashesh, T. A. A., and Osman, M. A. (2009). The impact of using leafcutting bees (Megachilidae hymenoptera) with different fertilization treatments on Alfalfa seed production. Rev. Int. Med. Cienc. Ac. 9, 134-141.

Shemesh-Mayer, E., Ben-Michae, T., Rotem, N., Rabinowitch, H. D., DoronFaigenboim, A., Kosmala, A., et al. (2015). Garlic (Allium sativum L.) fertility: transcriptome and proteome analyses provide insight into flower and pollen development. Front. Plant Sci. 6:271. doi: 10.3389/fpls.2015. 00271
Sheoran, I. S., and Sawhney, V. K. (2010). Proteome analysis of the normal and Ogura (ogu) CMS anthers of Brassica napus to identify proteins associated with male sterility. Botany 88, 217-230. doi: 10.1139/B09-085

Tan, F. C., and Swain, S. M. (2006). Genetics of flower initiation and development in annual and perennial plants. Physiol. Plant 128, 8-17. doi: 10.1111/j.13993054.2006.00724.x

van Doorn, W. G., and Woltering, E. J. (2008). Physiology and molecular biology of petal senescence. J. Exp. Bot. 59, 453-480. doi: 10.1093/jxb/erm356

Wang, X. C., Li, X. F., Deng, X., Han, H. P., Shi, W. L., and Li, Y. X. (2007). A protein extraction method compatible with proteomic analysis for the euhalophyte Salicornia europaea. Electrophoresis 28, 3976-3987. doi: 10.1002/elps.200600805

Wang, X. J., Li, X. X., Zhang, J. W., Feng, G. H., Zhang, S. Z., Huang, L. C., et al. (2011). Characterization of nine alfalfa varieties for differences in ovule numbers and ovule sterility. Aust. J. Crop Sci. 5, 447-452.

Wang, Z. F., Xu, A. K., and Yang, Y. F. (2007). Current study situation of alfalfa seed yield in china. Pratacult. Sci. 24, 43-50.

Woodson, W. R., Park, K. Y., Drory, A., Larsen, P. B., and Wang, H. (1992). Expression of ethylene biosynthetic pathway transcripts in senescing carnation flowers. Plant Physiol. 99, 526-532. doi: 10.1104/pp.99.2.526

Wu, Z. N., and Wei, Z. W. (2013). Floral morphology and development of alfalfa. Acta Agrect. Sin. 21, 159-166.

$\mathrm{Xu}$, J., and Zhang, S. Q. (2015). Mitogen-activated protein kinase cascades in signaling plant growth and development. Trends Plant Sci. 20, 56-64. doi: 10.1016/j.tplants.2014.10.001

Yu, S., Zhang, X. X., Guan, Q. J., Takano, T., and Liu, S. K. (2006). Expression of a carbonic anhydrase gene is induced by environmental stresses in Rice (Oryza sativa L.). Biotechnol. Lett. 29, 89-94. doi: 10.1007/s10529-006-9199-Z

Zeng, G. J., Li, C. M., Zhang, X. Z., Han, Z. H., Yang, F. Q., Gao, Y., et al. (2010). Differential proteomic analysis during the vegetative phase change and the floral transition in Malus domestica. Dev. Growth Differ. 52, 635-644. doi: 10.1111/j.1440-169X.2010.01199.x

Zhang, A. Q., Tan, D. Y., and Zhu, J. Z. (2005). Analysis on the pollination character and factors limiting the seed yield of alfalfa in pollination. Pratacul. Sci. 22, 40-45.

Zhang, D., Ren, L., Yue, J. H., Wang, L., Zhuo, L. H., and Shen, X. H. (2013). A comprehensive analysis of flowering transition in Agapanthus praecox ssporientalis (Leighton) Leighton by using transcriptomic and proteomic techniques. J. Proteomics 80, 1-25. doi: 10.1016/j.jprot.2012.12.028

Zheng, B. B., Fang, Y. N., Pan, Z. Y., Sun, L., Deng, X. X., Grosser, J. W., et al. (2014). iTRAQ-based quantitative proteomics analysis revealed alterations of carbohydrate metabolism pathways and mitochondrial proteins in a male sterile cybrid pummel. J. Proteome Res. 13, 2998-3015. doi: 10.1021/pr500126g

Zhou, S. P., Sauve, R., Fish, T., and Thannhauser, T. W. (2009). Salt-induced and salt-suppressed proteins in tomato leaves. J. Am. Soc. Hortic. Sci. 134, 289-294.

Zhou, S. P., Wei, S., Boone, B., and Levy, S. (2007). Microarray analysis of genes affected by salt stress in tomato. Afr. J. Environ. Sci. Technol. 1, 14-26.

Zhuang, W., Gao, Z., Wang, L., Zhong, W., Ni, Z., and Zhang, Z. (2013). Comparative proteomic and transcriptomic approaches to address the active role of GA4 in Japanese apricot flower bud dormancy release. J. Exp. Bot. 64, 4953-4966. doi: 10.1093/jxb/ert284

Conflict of Interest Statement: The authors declare that the research was conducted in the absence of any commercial or financial relationships that could be construed as a potential conflict of interest.

Copyright (C) 2016 Chen, Chen, Zhu, Hou and Mao. This is an open-access article distributed under the terms of the Creative Commons Attribution License (CC BY). The use, distribution or reproduction in other forums is permitted, provided the original author(s) or licensor are credited and that the original publication in this journal is cited, in accordance with accepted academic practice. No use, distribution or reproduction is permitted which does not comply with these terms. 